\section{All's fair when love is war}

\section{Laurent Keller}

SEMINAL fluid is bad for you - if you are a female fruitfly. On page 241 of this issue ${ }^{1}$, Chapman et al. report that increased exposure to products of the seminal fluid of male Drosophila melanogaster, transferred during mating, decreases female lifespan. Moreover, two other papers, by Harshman and Prout ${ }^{2}$ and Clark et al. ${ }^{3}$, reveal that although such products are detrimental to females they are beneficial tor males, in that they incapacitate sperm that a female has stored trom previous matings and raise the fraction of eggs fertilized by the last male to copulate. Clearly, there is no compromise when reproductive success is at stake.

In many organisms, there is a cost of reproduction' such that reproductive activity decreases either survival or future fertility ${ }^{4}$. In work antecedent to the new paper $^{1}$, Partridge and collaborators used spermless Drosophila male mutants to demonstrate that mating itself, not receiving and storing spcrm, is costly to females ${ }^{5,6}$. They now go further by sliowing that seminal-fluid products, made in the main cclls of the male accessory gland, are responsible for that cost.

In their experiments, Chapman et al. ${ }^{1}$ ensurcd that all females had enough sperm to fertilize their eggs by exposing them to wild-type males every third day. On the other two days females were mated to indor males (which produce seminal fluid but not spermatozua) or 'DTA' males (which produce no spermatozoa and no detectable main-cell products in their seminal fluid); DTA malcs are from a transgenic stock carrying a diphthcria toxin subunit A (DTA) that blocks protein trauslation in the main cells of males ${ }^{7}$. The lifespan of females mated to DTA males was significantly greater than thuse mated to tudor males, implying that it is the products of the main cells that reduce female lifespan. The exact compounds rcsponsible for this effect have yet to be identified.

Possible effects of behavioural differences between the two types of male were excluded by comparing the lifespans of females exposed to DTA males and to tudor males with microcauterized external genitalia, which behave normally but cannot mate. The lifespans were similar and did not differ from those of females mated with non-microcauterized DTA males. In short, the entire cost of mating is attributable to receiving male main-cell products. Finally, Chapman et al. demonstrated that main-cell products have a quantitative effect by mating females with males producing reduced amounts of main-cell products (males from stocks with reduced DTA production ${ }^{7}$ ). These remales had lifespans intermediate between those mated with males transferring no maincell products and with males transferring normal amounts

So why should males pass on these 'deadly' substances during mating? A possible explanation comes from the discovery that main-cell products are involved in sperm competition. Harshman and Prout ${ }^{2}$ found that mador males incapacitated up to 80 per cent of the

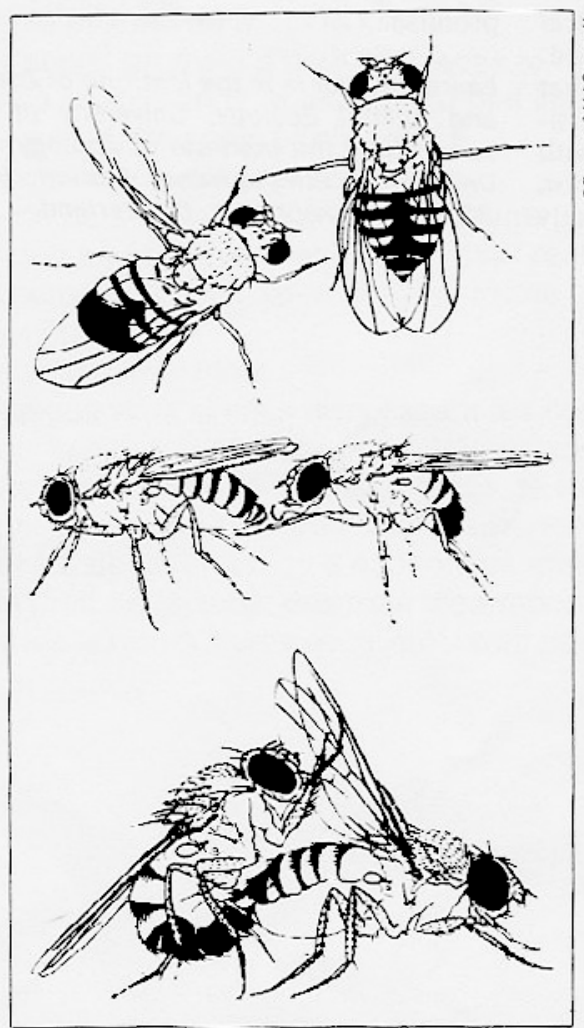

Courting disaster - stages of mating behaviour in $D$. melanogaster.

sperm stored by females during pievious matings, whereas DTA males had no effect on resident sperm. By transferring their main-cell products to females, males thus increase the proportion of offspring they sire, mcaning that the effect of these products on female lifespan might be a secondary effect of substances whose main function is to increase male reproductive success.

Given that difterences in postcopulatory sexual selection have strong effects on male fitness, we would expect to see little genetic variability in traits affecting sperm competition. But Clark et al. ${ }^{3}$ demonstrate just the reverse. They report highly significant differences among 152 lines of fruitflies made homozygous for the second and/or third chromosomes. both in male ability to displace sperm that females stored during previous matings and in male ability to prevent other males from removing their sperm from females.

Morcover, particular alleles at four out of seven accessory gland protcin $(A c p)$ genes were significantly associated with male ability to resist sperm displacement by males subsequently mating with the same females. Alleles of the four genes are not in linkage disequilibrium, implying that each of the four $A c p$ genes (or linked genes) probably independently influence the ability of males to resist sperm displacement. Because it is unlikely that each of the four $A c p$ genes is linked to genes influencing resistance to sperm displacement, and because these genes encode proteins that are transmitted to the females during mating, the $A c p$ genes probably have a direct influence on resistance to sperm displacement. This is the tirst evidence of genes influencing sperm competition.

Maintenance of genetic variability at genes affecting postmating scxual selection is thought-provoking, particularly as allelic variants at $A c p$ genes may account for a difference in male relative fitness of over 25 per cent ${ }^{3}$. Acp genes show high rates of evolution ${ }^{\circ}$. as do many secondary sexual characters. Possible mechanisms responsible for the variability at these genes include biased mutation (randum mutations will tend to maintain the average degree of relativc male fertilization efficiency beneath the optimum value ${ }^{9,10}$ ); non-transitive dominance hierarchy of sperm-competitive abilities (for example, if genotype $A A$ outcompetes $A B, A B$ outcompetes $B B$, but $B B$ outcompctes $A A$, a stable polymorphism can be maintained ${ }^{11.12}$ ); and an inter action between the male and female genotypes so that relative fitness of males with particular genotypes depends on the genotype of their mate. However that may be, the findings of Clark and colleagues,

\footnotetext{
1. Chapman. T., Liddle. L F Kalb. J. M.. Woifner, M. F. \& Dartringe I Narire 373. 241-244(1995) 2. Harshman. L. G. \& Prout. T. Evolution 48, 758-766 (1994).

3. Clark, A. G.. Aguade, M., Prout. 1.. Harsnman. L. G.\& Langley. C. H. Genetics (In the press).

4. Bell, B. \& Koufopanou, V. in Oxt. Surv. evol. Biol. Vol, 3 (eds Dawkıns. R. \& Ridley, M.) 83-131 (Oxford Univ. press, 1986).

5. Fowle:, K. \& Partsiagc. L. Naturo 338, 760-761 (1989)

6. Chapman. T., Hutchings. J. \& Partrifge. L. Proc. R. Soc. B253, 211-217 (1993)

7. Kalb, J. M. DiRenedetto. A.J. \& Woifner, M. F. Proc. natn Acad Sci. U.S.A. 90. 8093-8097 (1993).

8. Aguadé. M.. Miyashita, N. \& Langley, C. H. Genetscs 132 755-770(1992)

9. Lande, R. Evolution 34. 292-3Us (1980)

10. Pomiankowski. A.. Iwasa. Y. \& Nee. S. Evolution 45 1422-1430 (1991).

11. Prout. I. \& Bundgatard, J. Genetics 85, 95-124 (1977) 11. Keller \& Reeve, H. K Adv. Stud. Behav (in the pressi.

13. Wilkinson. G. S. Genet. Res. 63. 113-222 (1993).

13. Wilkinson. G. S. Genet. Res. 63. $31.2-222$.

15. Keller, L. \& Ross. K. G. Science 260, 1107-1110 (1993)

16 Cox.C. R. \& Le Boeuf. 8.J.Am. Nat. 111. 317-335 (1977).

17. Haig, D. Q. Rev. Biol. 68, 495-532 (1993)

18. Hurst, L. D. Proc. R. Soc. $8248,135-140$ (1992).
} 
together with reports of additive genetic variance in sexual characters ${ }^{13}$ and of effects of single genes on reproductive success $^{14,15}$, should lead to turther theorctical and empirical studies on the mechanisms maintaining variability at genes affecting fitness.

The work of Clark et al..$^{3}$ may also bear upon another issue - the causes underlying multiple mating by females. A benefit of multiple mating could be that, by mixing the sperm of several males, a female incicases the probability that her eggs are fertilized by a male with high fertilization efficiency, thus increasing the clances that her sons will have that trait $^{12,16}$. An assumption here is that there is a heritable component for differences in fertilization success of males, and Clark et al. show that this assumption is justified. Moreover, their study also indicates that females prefer males that have high fertilization efficiency: females mated with males that are good at resisting sperm displacement by other males are less likely to re-mate, and females mating with males that are good at displacing sperm tend to lay more eggs. Finally, females are morc likely to re-mate with males with high ability to displace sperm (raising, incidentally, the question of how they recognize these males).

A message emerging from these studies is that essential life-history traits such as longevily may not simply reflect an individual's interest: conflicts of interest within and between the sexes may also play a role, as may parent offspring and intragenomic conflicts ${ }^{17,18}$. Genetic analyses and the use of transgenic animals have proven to be powerful tools for dissecting such conflicts; combining them with physiological studies holds even greater promise.

Laurent Keller is in the institute of Zoology and Animal Ecology, University of Lausanne, and the Institutc of Zoology, Bern University, Ethologische Station Hasli, 3032 Hinterkappelen. Switzerland. 